\title{
Candido e Freud: fragmentos do vivido em Boitempo I
}

\author{
Cleusa Rios P. Passos*
}

\begin{abstract}
RESUMO
Antonio Candido, no artigo "Poesia e ficção autobiográfica", enfoca a questão da memória em autores mineiros, centrando-se, sobretudo, em Carlos Drummond de Andrade, Murilo Mendes e Pedro Nava. A leitura aqui pretendida rastreia sua proposta analítica relacionada ao primeiro poeta, mais especificamente a seu livro Boitempo I, sublinhando os fragmentos do vivido, capturados a partir de "cenas, casos e emoções da infância" do poeta. Candido destaca a construção de tais traços pelo eu lírico adulto, ou seja, a forma pela qual o presente atua no passado, ressignificando-o literariamente e sem ignorar diferentes olhares interpretativos, inclusive citando Freud, ao retomar J. Guilherme Merquior, incorporando, portanto, o apoio teórico da psicanálise. Na esteira da crítica, o ensaísta reafirma - e vai além - a presença do humor mais leve em Drummond, algo distinto do conjunto de sua obra e mais voltado para a "trama do mundo como espetáculo", ideia fulcral vinculada a uma associação entre o eu e a cultura, mas também a um "dar a ver", que pode ser pensado em termos psicanalíticos. Como na maioria de seus textos, Antonio Candido sintetiza finas reflexões que, desmembradas, abrem aos leitores vários caminhos interpretativos. É um deles que se intenta trilhar aqui.
\end{abstract}

Palavras-chave: Antonio Candido. Carlos Drummond. Boitempo I. Memória. Crítica literária. Psicanálise.

\footnotetext{
Professora titular departamento de Teoria Literária e Literatura da (FFLCH) Universidade de São Paulo (USP). Pesquisadora do CNPq e Coordenadora (com outra docente) do Grupo Crítica Literária e Psicanálise (FFLCH/ USP).
} 


\section{Candido and Freud: lived fragments in Boitempo I}

\section{ABSTRACT}

Antonio Candido focuses on the question of memory in the article "Poesia e ficção autobiográfica" in authors from the state of Minas Gerais, concentrating especially on Carlos Drummond de Andrade, Murilo Mendes and Pedro Nava. The objective of this text is to trace Antonio Candido's analytical proposal related to the first poet mentioned above considering particularly his book Boitempo I, underlining those lived fragments captured from "scenes, stories and emotions from the poet's childhood". Candido highlights the construction of such traces, which are created by the adult speaker, that is, the way through which the present acts in the past giving literarily new meaning to it without ignoring different interpretative viewpoints. He also quotes Freud when he retakes J. Guilherme Merquior, thus incorporating psychoanalysis as the theoretical framework. In the wake of criticism, the essayist reaffirms - and goes beyond it - the presence of a lighter mood in Drummond, something different from the whole of his work more focused on the world plot as a spectacle, central idea linked to an association between the I and the culture, but also the "creation of visibility" that can be thought in psychoanalytic terms. In most of his texts, Antonio Candido synthesizes fine reflections that once dismembered open up various interpretative paths. One of those is the intention of this paper.

Keywords: Antonio Candido. Carlos Drummond. Boitempo I. Memory. Literary criticism. Psychoanalysis. 


\section{Um tributo a Antonio Candido}

Em "Poesia e ficção autobiográfica", publicado no livro A educação pela noite $\&$ outros ensaios (CANDIDO, 1989), Antonio Candido faz um elucidativo levantamento de autores que produziram "autobiografias" em Minas, desde o século XVIII, mas seu intento maior é debruçar-se sobre uma "modalidade particular", ou seja, sobre os textos qualificados por ele como "autobiografias poéticas ou ficcionais", pertencentes a três renomados mineiros, do século XX, Boitempo I (1968) e Boitempo II (Menino antigo) (1973), de Carlos Drummond de Andrade, A idade do serrote (1968), de Murilo Mendes, e Baú de Ossos (1972) e Balão cativo (1973), de Pedro Nava.

Como não poderia deixar de ser, a questão da memória se destacará em todos eles, configurando-se de acordo com suas próprias singularidades, mas preservando sempre a escrita precisa e clara de um ensaísta que, em um parágrafo ou expressão, concentra dados substanciais da poética ou da prosa desses autores. Ao rastrear tais particularidades, percebe-se, na sutileza de seu olhar, o apuro da opção crítica que, sem mencionar nenhum viés teórico explícito, não abre mão de conhecimentos diversos que incluem reflexões de Freud.

Aliás, não custa lembrar que já no consagrado artigo "Crítica e sociologia", Antonio Candido considera literalmente "decisivos" tanto os fatores sociais como os psíquicos para a interpretação literária (CANDIDO, 1973, p.7) e, mais, argumenta que atuam, na "economia do livro", diferentes aspectos da cultura, inserindo-se em uma importante corrente crítica, propagada, com variações, por diversos autores. Basta citar Roland Barthes, que, anos depois, em sua Aula, afirma: "a literatura faz girar 
muitos saberes" (BARTHES, 1980, p.18) e qualquer um deles nunca é inteiro. A observação se mostra significativa não só ao olhar de Candido, mas também à psicanálise, saber aqui em destaque para a abordagem de um fragmento de "Poesia e ficção autobiográfica".

Cabe esclarecer que esse ensaio foi, inicialmente, uma palestra realizada por ele em Belo Horizonte em março de 1976 e publicada com o título "Autobiografia poética e ficcional de Minas" (CANDIDO, 1989, p. 215), um ano depois, revelando um intuito explícito de não tratar da "autobiografia em geral", mas, sim, de uma "modalidade particular", cujo intuito era comentar "alguns livros autobiográficos de cunho francamente poético e ficcional” (CANDIDO, 1989, p.53). A ressalva é importante porque, em 1977, dois anos após sua apresentação, Serge Doubrovisky cria, na quarta capa de sua obra Fils, o termo "autoficção", gerando, na década de 80 , discussões teóricas quanto à autobiografia em literatura e controvérsias em relação ao próprio termo.

O assunto não será discutido teoricamente, entretanto, Antonio Candido teve o cuidado de sublinhar que os textos selecionados eram da ordem do ficcional e/ou poético, tendo, inclusive, uma dupla e reversível leitura, isto é, poderiam ser lidos como "recordação" (e acrescento que a palavra comporta muito da construção ficcional) ou como "obra criativa" e a leitura de "dupla entrada" proviria de ela ser "simultânea, não alternativa" (CANDIDO, 1989, p. 53), ou seja, impossível ler tais textos ignorando o ato estético. Sem dúvida, aí aflora uma fina perspectiva crítica no que concerne à recepção de uma obra composta com traços do vivido, revelando em um artigo, aparentemente, sem a pretensão de se deter em questões teóricas da "autobiografia", um modo de ler outras produções literárias dessa natureza. 
Em linhas gerais, seu viés se centra no trabalho textual, tecido pelos autores citados, contemplando circunstâncias histórico-sociais e destacando que, em comum, os três autores retomam fragmentos de suas vidas, nos quais a presença do Imaginário recai sobre certos traços afetivos peculiares ao passado, (re)configurados graças à elaboração verbal, ao Simbólico. ${ }^{1}$ A proposta aqui perseguida aborda justamente tal ângulo, focalizando, de forma específica, faces de Boitempo I, de Carlos Drummond de Andrade, a partir do artigo de Candido e de algumas de suas sugestões, que, além de confirmadas, dão margem a interpretações, apoiadas, sempre analogicamente, em elementos teóricos da psicanálise. Impõe-se, agora, um tributo a Antonio Candido, pois sua capacidade de sintetizar ideias tem gerado, ao longo dos anos, inúmeros trabalhos de crítica literária. Este é mais um dentre tantos.

\section{Drummond: a lírica ficção do vivido}

Como se percebe em Boitempo I, e em sua continuidade, Boitempo II, o poeta busca algo perdido; dito de outra maneira, busca o tempo e o espaço pretéritos da meninice e de parte da adolescência (seus 14 anos), vividos em Itabira, e Candido bem o assinala: é o adulto, escreve ele, que, por meio de um olhar distanciado, procura (re)compô-los. Estabelece-se, assim, uma importante ciranda, na qual só a (re)construção imaginária do eu lírico em todos os poemas permite essa composição, filtrada pelo presente, que (re)cria restos de determinados episódios do

1 O termo é aqui compreendido como um dos três registros, na concepção lacaniana, da realidade humana. Vincula-se, portanto, ao Imaginário e ao Real e, em linhas gerais, identifica-se à linguagem, incluindo o inconsciente, bem como torna presente o sistema cultural a que pertencemos. (LACAN, 1975, p. 88). 
vivido e os transfigura literariamente. A posteriori, pontuaria Freud. No universo psicanalítico, tal termo tem dupla acepção, a de reelaborar os fatos pretéritos angustiantes e a de sublinhar que o tempo de agora desencadeia imagens pessoais anteriores $\mathrm{e}$ as contagia com impressões e eventos mais recentes, sinalizando que nunca se obtém nem o passado nem a verdade por inteiro. O presente interfere no tempo pretérito e este se desdobra no momento atual, (re)articulando-o e ressignificando o vivido. Nesse sentido, na reconstrução das lembranças - sempre lacunares-algo da ordem da ficção se instaura. No caso do autor mineiro, soma-se aí o dado poético.

Nas primeiras linhas de seu artigo, conhecedor do conjunto da obra de Drummond, Antonio Candido, ao mencionar a variação de estilo em Boitempo I e Boitempo II em relação a outros poemas, sublinha a insistência do "veio autobiográfico sem amargura", evidenciado, em parte, pela volta da "piada", do "humor cotidiano", das "situações corriqueiras"; características manifestas na seguinte citação de A astúcia da mímese, de José Guilherme Merquior, para quem o poeta assumiria nas duas obras:

um giro deliberadamente brincalhão, como se (para dizê-lo na língua de Freud), o humor drummondiano, reconhecidamente tão "superdeterminado", tão equívoco ou polissêmico, emergisse desta vez alacremente unívoco, solto e gaio, sem as restrições mentais da emotividade ferida ao choque do mundo. (apud CANDIDO, 1989, p. 54).

Ora, Candido não escolhe Merquior ao acaso, menos ainda tal passagem que inclui Freud, para quem a memória está presente ao longo de sua obra, vinculada à subjetividade e à linguagem. Além disso, a noção citada ocorre especialmente 
quando o psicanalista trata dos sonhos com o intento de esclarecer que superdeterminação ou sobredeterminação é um efeito da condensação, um dos processos oníricos, cuja função, ao lado do deslocamento e da figurabilidade, é a de encerrar múltiplas interpretações e, graças a esse elemento sobredeterminado, dá, a aspectos de menor importância, maior valor, sugerindo, assim, a força da censura na cena onírica. Vale, ainda, recobrar a citação de Merquior inteiramente em seu próprio contexto, encerrando-a: "É pelo menos a impressão que se retira de muita coisa de Boitempo I, a começar pelo lamentável acidente equestre de "Queda" (MERQUIOR, 1972, p. 50).

Em seguida, vale adentrar a cadeia do humor reconhecida pelos dois críticos, relendo o poema:

$$
\begin{aligned}
& \text { Cair de cavalo manso: } \\
& \text { coisa que só acontece } \\
& \text { uma vez em cada século. } \\
& \text { Por que, no século } 20, \\
& \text { logo a este acontecer? } \\
& \text { naquela rua? }
\end{aligned}
$$

Na última estrofe, o eu confessa a causa de sua queixa:

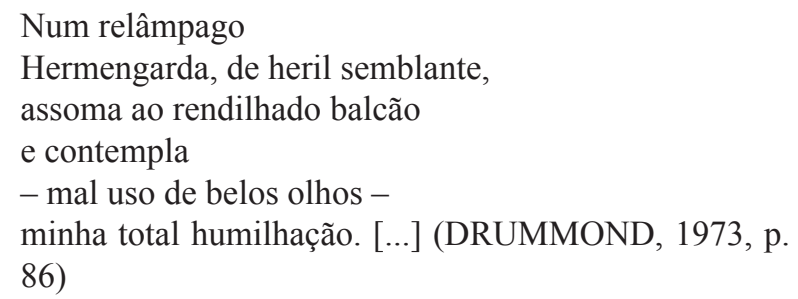

Ao acontecimento, prosaico e desonroso para o eu lírico, opõe-se a cena tradicional da donzela de semblante senhoril, que se coloca no espaço alto do balcão, distanciada e contemplativa, isto é, ela olha com admiração não para um altivo cavaleiro, mas, 
ao contrário, para sua queda, anteriormente anunciada ao leitor, já no título do poema. À ironia do tombo, acresce-se a falta de sincronia do tempo, peculiar à cidade pequena onde todos se conhecem: um jogo amoroso medieval, em pleno século 20 (?!), vem marcado pelo número arábico, corrente à época atual, que desloca o algarismo romano, clássico na representação dos séculos, marcando a anacronia dos costumes, geradora da humilhação final e descabida porque em descompasso com a época. Constrói-se a crítica irônica em relação ao provincianismo e o riso "grácil" aflora sem acidez, exatamente por tal descompasso.

Logo, se, em linhas gerais, a obra de Drummond comporta um humor ácido, mesclado à ironia e produzindo, por vezes, risos contaminados pela angústia, o que valida o nó sobredeterminado, referido por Merquior e ratificado por nosso ensaísta, Boitempo I escapa ao amargor da poética do autor itabirano como constante. Para Antonio Candido, essa tendência, extensiva a Boitempo II, poderia ser resultante do intuito "autobiográfico" de ambas as obras. Literalmente, ele declara: "Não se trata mais de poemas da memória em meio a outros de orientação diversa; mas unicamente de casos, cenas, emoções da infância de um emissor suficientemente caracterizado para se saber quem é." (CANDIDO, 1989, p. 54).

\section{As cenas poéticas}

Destaco aqui os termos: casos, cenas, emoções da infância; ou seja, fragmentos do vivido que retornam como traços pretéritos lacunares, demandando ressignificação. Aliás, se não há em Boitempo I a insistência da sobredeterminação, tais traços 
também permitem evocar a "língua de Freud", pois o trabalho mnêmico permite confluências entre o poeta e o psicanalista. Não por acaso, "(In) Memória” abre a obra do primeiro , preparando o leitor para os pedaços de vida - agora concretizados pelo verbo - que se tentará ilusória e paradoxalmente enfeixar, com lucidez das lacunas e da perda da memória da existência. Parece claro ao eu lírico que ficam restos de lembranças, condensados no vocábulo "resumido":

\author{
De cacos, de buracos \\ de hiatos e de vácuos \\ de elipses, psius \\ faz-se, desfaz-se, faz-se \\ uma incorpórea face, \\ resumo do existido. (DRUMMOND, 1973, p. 7).
}

A psicanálise sustenta que as lembranças jamais ressurgem como outrora vividas, mas reaparecem nas sensações angustiantes não resolvidas e em impressões, experiências e acontecimentos mais recentes, desencadeadores de imagens, cenas e episódios pretéritos, nem sempre relacionados explicitamente. Em linhas gerais, os poemas dramatizam liricamente o acordar das lembranças, comportando estilhaços da existência em unidades formais, cenas independentes, mas, paralelamente, partilham um fio comum - a (re)construção do vivido - que autoriza a leitura da obra em seu conjunto. Com acerto, Candido assinala que o intuito "autobiográfico", em Boitempo I, não vem marcado pela "auto-análise", "dúvida", "inquietude" ou "sentimento de culpa", se pensarmos na virtual totalidade da obra e que o poeta se inclui " deliberadamente na trama do mundo como parte do espetáculo" que se configura em alguns poemas de Lição de coisas. (CANDIDO, 1989, p. 55). 
Se retomássemos uma das reflexões de Doubrovsky sobre seu conceito de "autoficção", contida em "Mon dernier moi" (DOUBROVSKY, 2010 ), na qual ele propõe que "o vivido se conta vivendo" e a transfigurássemos pensando na produção poética de Drummond, assinalada por Candido, seria possível dizer que "o vivido se poetiza vivendo", ou seja, os acontecimentos da vida do sujeito lírico, de algum modo, se perdem, se inserem e se encontram na trama ampla da poesia, na qual Imaginário e Simbólico se transfiguram-nos versos que compõem a cena da escrita poética, espetáculo a ser oferecido ao olhar do leitor, deixando de ser mero acontecimento pessoal para se tornar cultural. Embora em alguns poemas o tempo verbal ocorra no pretérito, na maioria, o presente domina como se o sujeito pudesse re-viver o perdido no universo lírico, no momento da fatura dos versos.

Candido afirma, com relevância, que o poeta se vê de "fora para dentro". Em direção distinta, é possível aventar que esse "dar a ver" para o mundo (o Outro) também constitui uma forma de ele ser olhado, de se mostrar e mostrar sua criação, tornandose objeto do olhar alheio, o que o leva a privar-se do próprio, para que sua arte se desvele e exista. ${ }^{2}$ Dar visibilidade a seus versos permite ao poeta persistir no tempo, porém, paralelamente, ele deve aceitar os diferentes sentidos recebidos pela recepção de sua obra. E, aqui, volta-se a Candido, reiterando e ampliando a ciranda interpretativa de seu ensaio: o trabalho pessoal do eu lírico (que já se fez com aspectos de inúmeros saberes, nem sempre conscientes) torna-se cultural e, pode-se acrescentar, o poeta abdica de seu olhar em nome de uma função maior: a delegar a todos sua lírica.

2 Embora a incursão seja inspirada no "dar a ver" proposto por Lacan, ela ganha aqui outra perspectiva por se tratar de literatura. LACAN, 1973, p. 73). 
Voltando à afirmação relativa à certa leveza de bom número de poemas de Boitempo I, pode-se citar "O criador", "País de açúcar", " Orion", "Flor mágica noturna" ou "Cantiguinha", abaixo transcrito:

\author{
era um brinquedo maria \\ era uma estória maria \\ era uma nuvem maria \\ era uma graça maria \\ era um bocado maria \\ era um mar de amor maria \\ era uma vez era um dia \\ maria. (DRUMMOND, 1973, p. 71)
}

Há, ainda, versos mais brincalhões como os que compõem "Diabo na escada", "Os excêntricos" ou o poema narrativo "Suum cuique tribuere", cujo título latino permite o entendimento de "dar a cada um o que é seu", revelando o olhar do adulto para o pequeno e distante universo de Itabira. Vale a pena sua leitura:

\author{
$\mathrm{O}$ vigário decreta a lei do domingo \\ válida por toda a semana: \\ - Dai a César o que é de César. \\ Zé Xanela afundando no banco \\ vem à tona d'água \\ ardente \\ acrescenta o parágrafo:
}

- Se não encontrar César, pode dar a Sá Cota Borges que é mãe dele. (DRUMMOND, 1973, p. 113).

Do ponto de vista da psicanálise, a criação dos poemas citados parece obedecer ao principio do prazer, cuja função é evitar o desprazer, e, especialmente em Boitempo I, o desprazer de algumas recordações de outrora. Em "Cantiguinha", o eu lírico revisita o passado tratando, de modo poético, estereótipos das histórias infantis, graças ao emprego de formas nominais (não há subordinação), da ausência de pontuação e ao emprego 
de repetições, a saber: "era um"/ "era uma", expressão que insiste até se completar no "era uma vez", frase introdutória dos contos feéricos, que insinua um universo atemporal. Dispostos simetricamente, evocando cantares da infância, todos os versos terminam com o nome "maria", provocando uma expressiva reverberação (um/ uma/ mar/ amor/ dia) ao longo do poema. Se "Cantiguinha" se abre com esse vocábulo no diminutivo - grau de flexão peculiar ao mundo infantil - o cantar se encerra com o nome feminino, fundamental e escrito em letra minúscula, mimetizando o tamanho da criança, sugerindo a marca afetiva de um possível despertar do primeiro amor (a graça, o bocado, o mar de amor), imenso como o mar, fecho pleno do último verso.

Já em "Suum cuique tribuere", o eu lírico se vale igualmente do brincar infantil como forma de prazer na designação "Zé Xanela”, evocando lúdicas associações verbais: Zé Janela, Zé Canela, Zé Chinela etc., além da deliciosa ambiguidade da diferença de níveis culturais, que ironiza a pregação do vigário, tanto pelo título em latim, incompreensível aos fiéis, quanto pela menção ao imperador César para um público simples, que desconhece, em geral, a história de Roma, porém parece reconhecer a de seu cotidiano, a história comum do filho de Sá Cota Borges. O humor manifesta-se graças ao deslocamento de sentido do nome próprio, questionando o discurso do vigário, expondo sua inadequação e descompasso no que concerne ao nível de informação histórica de seus ouvintes.

O jogo de palavras se apoia no equívoco e na brevidade do poema, fulcral para desencadear o riso a serviço do princípio do prazer e do desejo do eu lírico, atuantes na transgressão da lei e da censura, rompidas por meio da introdução do nonsense do recado de Zé Xanela. Tal figura emerge do banco e de uma provável 
"bebedeira" de "aguardente" - palavra expressamente pontuada por sua divisão em dois versos água / ardente, elaborados por um eu lírico crítico e articulador do presente. Ao despertar, Zé Xanela busca cumprir, de algum modo, a imperativa lei cristã e, sem o saber, a descontrói, ao trocar as personagens e apequenar o César romano - a atitude, além de satirizar o pároco, dá voz aos fiéis que, análogos a Zé Xanela, não entendem a prédica, tornando-a ineficaz.

$\mathrm{O}$ eu lírico cria essa figura, que desvia a língua no próprio interior da língua, se recuperarmos considerações de Roland Barthes, causando um "estrago" benéfico à comunicação (BARTHES, 1980, p. 19). Ao tratar do nonsense, Freud menciona a dualidade "desconcerto-esclarecimento" (FREUD, 2006, p. 24) que o termo comporta e a possibilidade de sua transformação, às vezes, em chiste. De certo modo, Drummond vai nessa trilha, pois trabalha com a transgressão por via do humor, "dom precioso e raro" (FREUD, 2014 , p. 330) que faz o homem rir de si próprio, encarar, entre outros aspectos, a dor, o mal-estar, a finitude, e, particularmente no poema, o papel do humor seria o de desfazer um poder, totalmente deslocado do próprio ensinamento cristão, em uma pequena comunidade na qual o padre é um dos representantes da lei.

Em síntese, o eu poético realiza seu desejo de virar o jogo, ridicularizando um poder que inferiorizava os demais, valendo-se do princípio do prazer e do próprio mecanismo do humor, que precisa da "cena social" para ser bem-sucedido. Além dos fiéis, os leitores pactuam com tal cena, saboreando um duplo reconhecimento: a grandeza de César romano e seu apequenamento, efetuado pela palavra transgressora que desencadeia o riso e reduz o prestígio do padre para instaurar uma forma de contrapoder (BIRMAN, 2010, p. 188). 


\section{Duas formas de “Ubi Sunt?"}

Contudo, e de novo, Antonio Candido permite a abertura de um parêntese em seu ensaio, pois é possível assinalar que Drummond não ignora, em Boitempo I, o outro princípio freudiano, o de realidade, responsável pela recorrência de dois temas que se complementam: o renomado "ubi sunt" e a intensa dor da perda, constituindo-se exemplos deles "Ausência", "O resto", "Liquidação" "Os chamados", "O preparado" e o soneto "Repetição", aqui transcrito:

Volto a subir a Rua de Santana.
De novo peço a Ninita Castilho
a Careta com versos de Bilac.
É toda musgo a tarde itabirana.

Passando pela Ponte, Luís Camilo

(o velho) vejo em seu laboratório-

oficina, de mágico sardônico.

$\mathrm{Na}$ Penha, o ribeirão fala tranquilo

que Joana lava roupa desde o Império

e não se alforriou desse regime

por mais que o anil alveje a nossa vida.

Ô de casa!... Que casa? Que menino?

Quando foi, se é que foi - era submersa

Que me torna, de velho, pequenino?(DRUMMOND, 1973, p. 97)

No poema, o espaço e o tempo de hoje desencadeiam os de outrora, ao lado da leitura de Bilac, na revista Careta, da coleção da amiga Ninita Castilho. Entretanto, o musgo cobre a "tarde itabirana", insinuando sombra, ausência de flores, sementes e crescimento (de hoje em relação à imagem pretérita?), ou seja, embora viva, Itabira ganha a dimensão que o princípio de 
realidade lhe impõe e o eu lírico - volta-se, aqui, ao pensamento freudiano - desconfia da memória, percebendo que ela se vincula à linguagem, pois é o trabalho verbal que parece dominar a ideia da "repetição", no tempo atual, por meio da visão, na Ponte, da figura histórica do químico Luís Camilo e da presença da lavadeira Joana, representativa de um feminino ainda escravo, resquício dos tempos do Império.

Contudo, a repetição não é a mesma. Ela vem marcada pelo elaboração poética do sujeito lírico e sua rememoração. Basta perseguir suas metáforas: a magia de Luís Camilo marca a lembrança do menino, tocado pela profissão do velho químico da cidade; a palavra do ribeirão, testemunha persistente da opressão histórica da mulher, toma o lugar do (falar) humano que, desde o Império, pactua com um regime discriminatório; por fim, a imagem do "anil" se impõe, deslocada de sua clássica função de alvejar roupa, para alvejar vidas. Tal deslocamento não buscaria provocar um estranhamento no leitor com o intento de revelar sua cegueira diante da cena repetitiva de Joana? Repetir comportaria, assim, faces distintas: a do eu lírico que procura retornar no tempo e espaço passados e a da história que sugere a ausência de mudança da condição de trabalho da mulher pobre e, de maneira mais ampla, do pequeno trabalhador sem qualificação.

$\mathrm{Na}$ estrofe final, de modo mais explícito, as interrogações (o constante "ubi sunt?") evidenciam a transfiguração das lembranças da história singular do eu lírico e, paralelamente, da coletiva, pois as incertezas explodem na constatação inquieta e inexorável da passagem temporal que atinge a quase todos nós: Que casa? Que menino? Será que aconteceu? O que torna verdade as imagens infantis na velhice? Além disso, a ciranda do tempo e o não saber exato sobre o vivido expõem outros e imprecisos questionamentos: será que é preciso obter a verdade? 
Parte dela já não estaria nessa ficção poética que Drummond nos lega? Sem dúvida, os poetas sabem o que dizem: Fernando Pessoa também nos contempla com ideia semelhante nos versos finais de seu "Pobre velha música": "E eu era feliz? Não sei:/ Fui-o outrora agora." (PESSOA, 1969, p. 140 ).

A ideia de "ficção poética" em Boitempo I remete a novos elos. Basta ler "Primeiro conto", pequena obra-prima, que também poderia abrir a obra, pois escancara a ideia do inevitável "não saber", a angústia e a letra (o despertar da poeta já denunciava a luta com as palavras?):
O menino ambicioso
não de poder ou glória
mas de soltar a coisa
oculta no seu peito
escreve no caderno
e vagamente conta
à maneira de sonho
sem sentido nem forma
aquilo que não sabe.

A segunda estrofe contém uma espécie de contido lamento:

Ficou na folha a mancha

do tinteiro entornado, mas tão esmaecida

que nem mancha o papel.

Quem decifra por baixo

a letra do menino,

agora que o homem sabe

dizer o que não mais

se oculta no seu peito? (DRUMMOND, 1973, p. 79).

Em outros termos, o eu lírico adulto dá forma ao que o menino ignorava, mas reforça a ideia da desconfiança do tempo que corrói a memória, só lhe restando a interrogação pela metáfora da mancha: como decifrar a linguagem borrada da infância? Uma 
vez ainda, Drummond atinge a todos. E se a psicanálise amplia a questão, Antonio Candido bem o observa, ao considerar que "a experiência pessoal se confunde com a observação do mundo", tornando os traços autobiográficos "história simultânea dos outros e da sociedade" (CANDIDO, 1989, p. 55), sem abdicar do espaço mineiro; por outro lado, a história do "eu" não se elabora sem a dos outros. Embora de ordem distinta, o legado é recíproco. O ensaísta aponta, igualmente, que o afastamento entre o adulto e o passado se destaca em várias composições (linguísticas) de Boitempo I e II:

[...] generaliza o que pareceria restrito particular, e se revela no fato de o Narrador poético falar indiferentemente "eu" ou "o menino", e usar certa indeterminação que deixa apenas pressuposta a $1 .^{\mathrm{a}}=3$. $^{\mathrm{a}}$ ou a $3 .^{\mathrm{a}}=1$. $^{\mathrm{a}}$ pessoas em muitos poemas. $\mathrm{O}$ "eu" é "ele", mas "ele" é "eu"; são o mesmo, mas podem ver-se do lado de fora e de longe. (CANDIDO, 1989 p. 55).

Nessa direção, cabe reler "Herança", poema no qual o doloroso sentimento de perda e a conhecida contraposição drumondiana, a seca ironia (que embora não prevaleça no conjunto de Boitempo I, não deixa de aflorar), além de evocarem muito da "Confidência Itabirana", de Alguma Poesia (1930), reconstituem o universo econômico-social de outrora:

De mil datas minerais

com engenhos de socar

de lavras lavras e mais lavras

e sesmarias

de bestas e vacas e novilhas

de terras de semeadura

de café em cereja (quantos alqueires?)

de prata em obras (quantas oitavas?)

de escravos, de escravas e de crias

de ações da Companhia de Navegação do Alto Paraguai da aurifúlgida comenda no baú 
enterrado no poço da memória restou, talvez? este pigarro. (DRUMMOND, 1973, p. 63).

Aqui, a construção é semelhante aos textos já citados. Predominam as frases nominais, pois os bens financeiros, indicativos (alguns quase incontáveis) do patrimônio de antigamente - que se estendem de terras, gado e minerais a seres humanos, de ações à honraria social -, não passam hoje de mera enumeração mnêmica. Resta ao eu lírico um verbo (“enterrar”) no particípio passado, que rompe inexoravelmente a lista de bens e se converte em parte da metáfora "poço da memória", que, por sua vez, se desfaz facilmente, pois a memória não é um grande buraco, nem um reservatório para resguardar acontecimentos e emoções.

Vale reiterar que, em psicanálise, a memória escapa ao senso comum, ao estabelecer elos com o desejo, o inconsciente, os afetos, as experiências e a linguagem. Segundo Freud, entra aí o tempo do inconsciente que obedece a uma lógica própria, diversa do tempo cronológico, e atua na (re)construção das lembranças, (re)articulando e (re)criando traços do passado, no presente. Conforme se viu, esse processo ocorre "a posteriori" ("nachträglich", (FREUD, 2006), ou seja, as marcas mnêmicas, inscritas desde a infância, podem ser ressignificadas em outro momento da vida, contagiadas por fantasias, sonhos e lembranças ulteriores. Guardadas as devidas diferenças, se, na análise freudiana, é possível encontrar novos nexos e interpretações do passado a cada fala, na literatura se obtém resultados semelhantes a cada (re)leitura. Contudo, no primeiro caso, nem sempre tal processo se realiza, pois, muitas vezes, as marcas mnêmicas retornam sob a forma de repetição, permanecendo irrepresentáveis e fora do campo da linguagem, embora interfiram, com intensidade, no presente. 
Nos poemas de Boitempo I, a repetição não é um sintoma, mas um recurso literário. Em "Herança", ela atua na lembrança, ao longo dos onze versos, insistindo na perda dos bens de outrora como algo incessante, insinuando a dor sem o explicitar e desvelando o passado em função de sua contraposição, a saber, o mísero, duvidoso e diminuto fecho que encerra o último verso: "este pigarro". Ora, do ponto de vista cultural, o resto que fica vale bem mais do que o referido pigarro. Ao recobrar fatos, que podem ser comprovados pela história de Itabira, o eu lírico não só evidencia uma nítida recordação de sua cidade, integrada à coletiva, como, da perspectiva psicanalítica, revela sobrepor-se ao esquecimento que o desprazer das perdas poderia provocar. $\mathrm{O}$ inventário dos bens perdidos, espécie de registro poético, destaca não apenas o respeito ao princípio de realidade, mas também a maestria de dar forma lírica à dor, verbalizá-la de algum modo, embora com rasgos irônicos. À primeira vista, só the resta o pigarro, o som surdo que dá voz ao corpo, resultante de uma irritação da garganta, uma mucosidade de que se quer livrar.

No entanto, se tal viscosidade causa mal-estar, ela é igualmente defesa do organismo. E a maior defesa do eu lírico é a reelaboração da lembrança das perdas por meio da poesia. Ele não deixa de inserir, no verso final, o pequeno advérbio “talvez?", - a dúvida constante de grande parte de sua obra, o conflito peculiar ao humano que persiste. O que pesaria mais? Fica, então, a pergunta: e suas perdas? Sobretudo, porque elas são também as dos habitantes de sua cidade. Mas, é preciso reafirmar que resta, ao sujeito lírico, a criação - legado maior e ainda prazeroso, oferecido aos itabiranos e a seus leitores. Ele sabe dar forma poética às dores e aos fantasmas, sabe reelaborar as perdas da existência de qualquer sujeito frente ao tempo, à 
história e à finitude. $\mathrm{O}$ poeta dá a ver ao mundo o prazer das imagens literárias de Boitempo I. E, nesse momento, reencontrase Antonio Candido e sua feliz interpretação:

Em Boitempo e Menino antigo a estilização literária é aplicada para narrar a existência do eu no mundo: particularizadora, de um lado, na medida em que destaca o indivíduo e seus casos; mas, de outro, generalizadora, porque é simultaneamente descrição de lugar e biografia de grupo. Os fatos e sentimentos, as impressões e ambientes, que são o ponto de partida da elaboração literária, pesam com maior impureza do que na obra lírica anterior; e, como acontece nos livros de memórias pessoais, a elaboração da forma não chega a dispensar o sentimento vivo do objeto, ponto de partida, porque o escritor quer justamente pô-lo na luz da ribalta, embora poeticamente transfigurado. (CANDIDO, 1989, p. 56).

Às lembranças pessoais, "a luz da ribalta" e o sabor do verbo.

\section{Referências}

BARTHES, Roland. Aula. Tradução de São Paulo: Cultrix, 1980.

BIRMAN, Joel. O rei está nu. Contrapoder e realização de desejo, na piada e no humor. Revista Psicologia Clínica. Rio de Janeiro, v. 22, 2010.

CANDIDO, Antonio. A Educação Pela Noite \& Outros Ensaios. São Paulo: Ática, 1989

CANDIDO, Antonio. Autobiografia poética e ficcional de Minas. In: SEMINÁRIO DE ESTUDOS MINEIROS, 4., 1976, Belo Horizonte. Anais... Belo Horizonte: Edições do Cinquentenário da Universidade Federal de Minas Gerais, 1977. 
CANDIDO, Antonio. Literatura e Sociedade. 3. ed. São Paulo: Companhia Editora Nacional, 1973.

DRUMMOND DE ANDRADE, Carlos. Boitempo \& a falta que ama. 2. ed. Rio de Janeiro: Sabiá, 1973.

FREUD, Sigmund. Carta 52. (1896). In: FREUD, Sigmund. Obras completas. Rio de Janeiro: Imago, 2006. v. 1. FREUD, Sigmund. In: FREUD, Sigmund. Obras Completas. São Paulo: Companhia das Letras, 2017. v. 7.

FREUD, Sigmund. Recordar, repetir, elaborar. (1914). In: FREUD, Sigmund. Obras Completas. São Paulo: Companhia das Letras, 2010. v. 10.

FREUD, Sigmund. O humor. (1927). In: FREUD, Sigmund. Obras Completas. São Paulo: Companhia das Letras, 2010. v. 17.

LACAN, Jacques. Le séminaire/livre XI. Les quatre conceptes fondamentaux de lapsycahanalyse. Paris: Seuil, 1973.

LACAN, Jacques. Le séminaire/ livre I. Les écrits techiniques de Freud. Paris: Seuil, 1975.

MERQUIOR, José Guilherme. A astúcia da mímese (ensaios sobre lírica). Rio de Janeiro: José Olympio, 1972. 